\title{
MAL-ESTAR NO DIREITO: NOTAS SOBRE A FILOSOFIA DO DIREITO E SUA RELAÇÃO COM LINGUAGEM E A IDEOLOGIA JURÍDICA
}

\author{
MALAISE IN LAW: ENSAY ABOUT THE MALAISE IN LAW AND YOURS \\ RELATIONSHIPS WITH THE LINGUAGE AND IDEOLOGIE
}

\section{Michel Zaidan Filho ${ }^{1}$ \\ Edlene Maria Neri ${ }^{2}$}

\section{RESUMO}

Este ensaio trata da crise da filosofia do Direito, a linguagem jurídica cimo sistema ideológico e de uma nova proposta de hermenêutica judicial, que se afasta do positivismo jurídico, ao dialogar com as ciencias humanas, seguindo as pegadas da sociologia do Direito.

Palavras chaves: crise; direito; ideologia; linguagem; hermeneutica.

\section{ABSTRACT}

This ensay study the relationships between the law, the filosophie of the law and the lenguage like ideologic sistem. And presents the hermeneutic sociologique of the society.

Keywords: law; ideologie; lenguage; hermeneutics.

\section{INTRODUÇÃO}

Foi com o filósofo alemão Immanuel Kant que se erigiu a moderna filosofia do Direito e da Moral (KANT, 1980). A partir da arquitetônica de sua três críticas (Crítica da Razão Pura, Crítica da Razão Prática e a Crítica do Juízo), e mais a metafísica dos costumes, Kant - depois de Descartes - inaugura a chamada filosofia da consciência ou do sujeito. Depois do filósofo alemão, todos ficamos kantianos (uns mais, outros menos). Kant, como Hegel, nos obrigou a interpreta-lo ou reinterpretá-lo de mil e uma maneiras dando razão a quem já disse que cada grande pensador obriga os pósteros a explicitar o seus pensamentos de diferentes maneiras.

$\mathrm{O}$ essencial da visão iluminista do autor era a defesa intransigente de um sujeito ético e epistemológico autônomo, crítico e individual, capaz de decidir e pensar por si próprio, sem ajuda de ninguém (Sapere Aude). O fundamento do sujeito moral estaria exatamente nessa liberdade e autonomia da vontade, tornando-o, inclusive, imputável e moralmente responsável pelos seus atos. Essa famosa autonomia da vontade conduziu à majestade do "imperativo categórico" e do caráter universalmente vinculante da ética e do direito kantianos, garantidos pela existência de um "eu transcendental" que uniformizaria os "eu" individuais da perspectiva da consciência normativa e moral.

Essa visão majestosa da Ética foi impiedosamente criticada por Frederico Nietzsche, à luz de uma filosofia da "vontade de poder", segundo diz-se, baseado numa compreensão heraclitiana da vida, a luta dos contrários, o devir, o fogo e o eterno movimento das coisas (NIETZSCHE, 1971). Nietzsche desconstruiu a elegante filosofia do sujeito moral de Immanuel

\footnotetext{
${ }^{1}$ Professor titular da Pós-graduação de Direito da UFPE. Edilene Maria Neri é doutoranda em Direito na Pósgraduação de Direito, da UNICAP.

${ }^{2}$ Doutoranda em Direito na Pós-graduação de Direito, da UNICAP.
} 


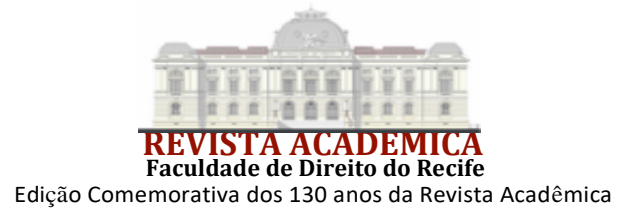

Kant, a partir da "Genealogia da Moral", (NIETZSCHE, 1971) e de seu pensamento cosmológico do acaso e da necessidade (além do eterno retorno do mesmo), dando origem a uma filosofia da transvalorização dos valores (o niilismo positivo e criador) e do advento do super-homem. (NIETZSCHE, 1979).

O desafio contemporâneo foi como reconstruir a ética e o direito depois da crítica nietzschiana ao iluminismo moderno. Essa tarefa não foi fácil nem incontroversa entre os filósofos posteriores a ele.

Aqui, se apresentaram aqueles autores que se colocam no campo da Pós-modernidade, do relativismo e da filosofia da Linguagem.

$\mathrm{E}$ os que procuraram salvar o conteúdo emancipatório e crítico da modernidade, usando a teoria dos atos de fala comunicativos. De um lado, Foucault e os pós-estruturalistas. (FOUCAULT, 1980) De outro, Habermas e seus discípulos. (HABERMAS, 1987) No meio, a filosofia da Linguagem, como o novo médium de explicação da realidade. Há, também, os intermediários que uniram a crítica da razão moderna ao historicismo cultural, político e social, como Boaventura Santos, (SANTOS, 1986) hoje associado a uma cruzada pela descolonização do saber, as chamadas "epistemologias do sul" e a "hermenêutica diatópica".

Na Pós-graduação de Direito, das nossas universidades, há uma diversidade de autores e professores que se aliam ora com uma espécie de ceticismo metodológico, na ciência, na ética e na filosofia, filiando-se à escola retórica do pensamento jurídico; há os pós-modernos e sua aproximação como os autores pós-estruturalistas (Deleuze, Guatari, Lacan, Nietzsche e Foucault) e há os que defendem a crítica á razão, inclusive á razão comunicativa, em nome de uma racionalidade alternativa que nem seria discursiva ou instrumental, mas produzida em outros contextos pós-coloniais e não-europeus, E aqui não há como não recordar as críticas de Mary Young à razão comunicativa e Boaventura de Souza Santos, com a sua concepção multicultural dos direitos humanos e sua hermenêutica diatópica.

Mais uma vez, como fazer o diálogo entre a razão moderna e a diversidade étnica, cultural dos povos. Europa, América latina, Ásia e África? - É possível? Sem cair no risco de um historicismo conservador que faça uma apologia do atraso (o jeitinho brasileiro, jeca tatu, a lei de Gerson, Macunaíma), ou se cair num relativismo ético e gnosiológico perigoso, em nome do respeito às diferenças?

Esse é o "ponto dollens" da discussão. Qual é afinal a racionalidade alternativa à moralidade kantiana do sujeito moderno, da razão discursiva e do relativismo da pósmodernidade?

Como se ver, criticar é fácil: construir algo novo já é mais difícil. Antes de se exigir dos alunos uma moralidade jurídica e filosófica alternativa, é necessário terlapresentar uma abertura para o diálogo e o diferente. O novo não sai por obediência ou submissão à vontade dos mestres. Só com generosidade intelectual. Apresentaremos, a seguir, um panorama dos autores que trataram da linguagem jurídica como sistema ideológico.

\section{DIREITO, LINGUAGEM E IDEOLOGIA}

A relação do direito sobre as diversas visões da linguagem como sistema ideológico, por alguns dos mais importantes teóricos do direito e filósofos da linguagem. O primeiro a ser abordado é Ludwig Wittgenstein, que entende a linguagem como um meio desprovido de pretensões de validade. (WITTGENSTEIN, 1991) A obra desse autor costuma ser divivida em duas fases. Vamos nos ater à segunda fase: a crítica da função representativa, enunciativa ou descritiva da linguagem humana. (Investigações filosóficas, 1991) Neste sentido, a linguagem nem implica num sujeito da enunciação (o dono da verdade e da mentira), nem implica no conceito de ideologia, como distorção da imagem do mundo, e forma de dominação social. A teoria de Wittgenstein é que há na linguagem vários jogos distintos, sem classificação ou hierarquia de valor.

TAL 


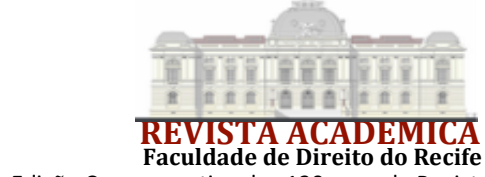

Edição Comemorativa dos 130 anos da Revista Acadêmica

Um desses jogos é o da verdade (na ciência, na filosofia, no direito). Essa modalidade de jogo de linguagem implica na aceitação tácita pelo locutor de que os signos correspondem ou representam a realidade, as normas ou as expressões estéticas. Mas só nessa modalidade.

Já a posição de Nietzsche, Foucault, Deleuze e Guatarri é aquilo que se chama de retórica ou neonominalista. Diz que os signos da linguagem humana são meras convenções, acordos tácitos entre as pessoas, mas que não correspondem a nada. Pior, são signos ou discursos a serviço de imperativos de poder. Em si não são falsos ou verdadeiros, mas contém efeitos de verdade a partir da política de verdade adotada pela sociedade. Essa visão cética e relativista da linguagem não prevê nem sujeito, nem juízo de valor cognitivo ou moral sobre os fatos da linguagem. Só o desempenho, a performance prática dos atos de fala. É o uso pragmático das palavras, para manipular os objetos e pessoas, a partir de "relações de poder onimodas e instáveis".

Em seguida, vem a visão marxista tradicional da ideologia e linguagem. (MARX, 1980). O que é a ideologia? É o uso da linguagem para produzir uma imagem ilusória, distorcida, falsa da realidade. Quem detém a ideologia? A classe dominante (sujeito). Ela tem a visão correta das relações sociais e usa a ideologia para consolidar, manter a sua forma nua e crua de dominação sobre outra classe social. Essa teoria implica no sujeito da enunciação e na distinção entre pensamento correto e pensamento falso. A linguagem jurídica é ideológica porque serve para racionalizar a forma de dominação de uma determinada classe sobre a outra. Há variações nessa linha. Althusser é um marxista estruturalista que afirma que a ideologia não tem história nem sujeito. Ela produz o sujeito. Ela não tem oposição. Gramsci se opõe a Althusser e diz que há uma luta no interior dos aparelhos ideológicos, entre a hegemonia da classe dominante e a contrahegemonia dos dominados. Gramsci distingue entre hegemonia e dominação. Entre signos ideológicos e signos revolucionários. (GRAMSCI, 1975).

Agora vem o Habermas, que muda inteiramente a discussão sobre a linguagem, para dizer que o sujeito é a ideologia. (HABERMAS, 1987) Para começar, segundo ele, o sujeito da enunciação não é o indivíduo monólogo, solitário, kantiano. É produto do diálogo, da inter-relação, do processo argumentativo de provas e contraprovas. A verdade é o resultado do acordo, depois do processo argumentativo, que ele chama de discurso filosófico. Habermas se afasta de Nietzsche, Foucault e Wittgenstein, porque ele faz uma tipologia de atos de fala (baseado em linguistas anglosaxões como Austin, Pearce, etc). Conforme ele, existem basicamente três tipos de atos-fala: os que são meramente descritivos (locucionários), os comunicativos e os perlocucionários. Aqueles a que se chama de ideológicos são os perlocucionários, porque eles não visam a provar discursivamente nada a ninguém. Eles visam a induzir você fazer o que quero, sem você saber, pelo efeito do que eu digo, independentemente de ser falso ou verdadeiro. Os atos de fala comunicativos possuem pretensões de validade cognitiva, moral ou estética, que podem ou não ser aceitas pelo interlocutor a partir das provas e contraprovas apresentadas.

Habermas, Foucault, Nietzsche e Marx falaram do direito. A obra de Habermas sobre a concepção discursiva do direito é o livro "Direito e democracia", seu segundo volume. O de Foucault é "Direito e as formas jurídicas", bem como "Vigiar e punir". Nietzsche é o livro "Genealogia da moral". Em Marx, é "A ideologia alemã". Em Pachukanis, a obra é "Marxismo e direito". Em Althusser, a obra "Aparelhos ideológicos de Estado". Em Gramsci, a obra "Notas sobre o príncipe, a política e o Estado Moderno". Em suma, para Habermas, Direito é forma de regulação social (faz parte do estado moderno); para Foucault, uma forma de controle social; e para Marx, racionalização da forma de domínio burguês através da ideologia jurídica.

Toda essa discussão filosófica serve, naturalmente, como antessala para uma revisão da hermenêutica jurídica de tipo positivista, atenta ao significado da norma posta, à luz da jurisprudência e da tipificação penal, quando se trata de julgar crimes. Ora, o que se está propondo nesse texto, a partir desse preâmbulo teórico-metodológico é um outro tipo de hermenêutica que uma pesquisadora chamou de "sócio-jurídica" ou de uma "antropologia 


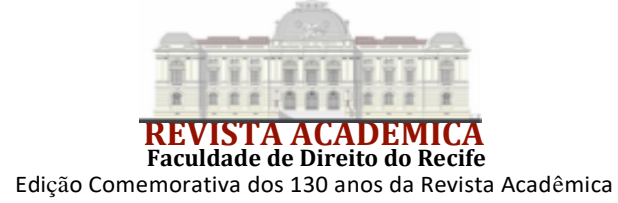

jurídica", na análise de crimes de sangue entre grupos populares, entre nós (NERI, 2021). Ou Seja, a ideia de que a decisão judicial, para não falar nos próprios signos jurídicos, precisa ser mediada pelo contexto cultural, antropológico, histórico dos atores envolvidos. Este tpo de exegese da lide em questão, tem de dialogar com outros saberes, além da Ciência Jurídica isolada. Dialogar com a História, a Sociologia, a Antropologia, a Semiologia, a Filosofia etc.

\section{POR UMA OUTRA HERMENÊUTICA JUDICIAL}

Devemos avaliar, agora, como os limites da hermenêutica tradicional, principalmente, os impostos pelo os discursos da acusação e da defesa no Plenário de um Tribunal do Júri se desencadeiam de forma a convencer o Corpo de Jurados de que seus argumentos contêm a realidade do

fato e, portanto, que eles são verdadeiros. Cada grupo escolhe uma estratégia de ação dentro das opções possíveis e de acordo com as regras predeterminadas do CPP. Os embates também se evidenciam na tonalidade da voz, por meio das expressões faciais e corporais, na linguagem utilizada, na ironia, uso de certas palavras, de certas expressões, de maneira a persuadir os jurados. Nota-se a montagem de um teatro, onde os opositores se apropriam de fragmentos de um fato do passado e passam a reconstruí-lo no presente, carregado de valores morais, éticos, culturais dos atores envolvidos na disputa jurídica, o que faz lembrar o pensamento nietzschiano de que o homem é criador de valores, porém, esqueceu-se da própria criação, transformando-os em algo "transcendente", "eterno" e "verdadeiro", quando os valores nada mais são do que "humano, demasiado humano".

Ocorre que tal construção ou interpretação pelos operadores judiciais permanece presa ao ordenamento jurídico, porque acreditam na univocidade do sentido das regras interpretativas, não permitindo efetivamente obter um quadro completo e variado da vida cotidiana dos grupos populares. Isto significa dizer que as informações contidas nos autos do processo-crime representam versões da realidade, já que sofrem as limitações inerentes à linguagem, não consegue dar conta da complexidade da vida. Além disso, a linguagem não possui um sentido unívoco ou definitivo, mas representa uma atividade de criação e recriação diária, passível de compreensão a contextos determinados, dando margem a interpretações com sentidos variados. Daí que, o desafio de uma hermenêutica jurídica é compreender os aspectos da vida em sociedade, que envolvem fatores históricos, culturais, econômicos, políticos que precisam ser enfrentados numa decisão judicial.

Para Habermas, segundo a professora Virgínia Colares (COLARES, 1990) a linguagem é uma forma de ação. O simples falar implica na necessidade de uma compreensão mútua, um ideal de exatidão e veracidade, uma sinceridade. Sendo uma atividade que adquire significados nas relações sociais, para a professora Virgínia Colares, no contexto institucional da Justiça, as condições de uso que são múltiplas possibilitam a criação de um novo objeto. Isto implica dizer que os desafios impostos aos intérpretes do Direito na prática cotidiana da Justiça precisam ser encarados com clareza e humildade, uma vez que não se conhece o todo, apenas parte, fragmentos do mundo - é ilusão acreditar ou pensar que se sabe o que está acontecendo - o "mundo da vida" - por ser esta uma estrutura mais complicada.

A hermenêutica é uma atividade que não se preocupa apenas com a superfície, mas com o texto, com sua profundidade, de conformidade com o contexto considerado. Daí a razão de sua aproximação com a pragmática, uma vez que ambas enxergam a verdade como consequência de uma interpretação. Porém, isto não equivale um "vale tudo", pois a pragmática considera a linguagem como ação que produz efeitos e consequências em contextos determinados. Por sua vez, no campo do Direito tradicional, os fundamentos de uma decisão judicial se mostram sempre idênticos a si mesmo, como se houvesse um tempo único a ser decifrado e interpretado, independentemente dos aspectos históricos e culturais. 


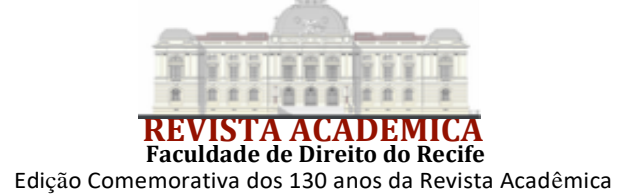

Raquel Sparemberger (SPAREMBERG, 2003), ao analisar a polêmica quanto à natureza jurídica da Ciência do Direito travada entre Hans Kelsen e Eugen Ehrlich, afirma que enquanto o primeiro preocupado com uma Teoria Pura do Direito, visa libertar a Ciência Jurídica de elementos sociais, o segundo, enxerga o Direito como uma ciência mutável que sofre as especulações de cunho sociológico. Para Ehrlich, segundo a autora, não cabe ao jurista ficar restrito aos códigos, às leis (documentos legais). O jurista deve se preocupar com as relações jurídicas (documentos jurídicos), ou seja, com o Direito como ele é, como ele se dá. Disso resulta que "o Direito vivo", é aquele vivido pelas comunidades, nas relações diárias, nas práticas costumeiras, que necessitam ser observado e, portanto, diferente do estabelecido nos códigos. Por isso, para Eugen Ehrlich, continua a autora, a ciência e o ensino não podem se restringir ou explicar apenas o que está escrito na lei.

O historiador Sidney Chalhoub (CHALHOUB, 2001), buscando "decifrar" os rituais de violências no modo de vida da classe trabalhadora carioca no início do século $\mathrm{XX}$, viu que "a rixa surge da própria dinâmica de funcionamento e ajuste de tensões dentro do microgrupo sociocultural estudado," do que conclui que as alegações iniciais do crime, relatadas com frequência pelos depoentes nos processos-crime, devem ser vistas com cautela, pois se trata apenas de antecedentes imediatos aos homicídios. A leitura exaustiva e comparativa, segundo o autor, demonstra a rixa como um acontecimento político enraizado no modo de vida dessas populações pobres, que pareciam possuir princípios próprios de resolver os seus conflitos, muitas vezes bem diferentes daqueles engendrados pelos grupos dominantes.

Maria Sylvia de Carvalho Franco(FRANCO, 1979) ao analisar os crimes de homicídio ocorridos entre os caipiras na região cafeeira do Vale do Paraíba, no século XIX, observa que as soluções dos conflitos violentos entre esses indivíduos por meio da luta e da força irrompiam nas relações de momento, ou seja, sem que necessariamente os vínculos amistosos ou hostis anteriores entre eles tivessem contribuído. As ocorrências evidenciadas pela autora mostram a violência como um padrão institucionalizado de comportamento entre esses grupos caipiras.

A leitura do processo-crime de homicídio aqui analisado nos revela que as circunstâncias antecedentes ao momento da morte da vítima estão permeadas por discussões, humilhações, ofensas morais e físicas mútuas. O momento do crime constitui-se no terceiro encontro ocorrido naquele dia entre os contendores. As três situações foram acompanhadas de perto por agressões morais e físicas recíprocas, bem como todas elas presenciadas pela vizinhança. Acredita-se que o crime de sangue tenha sido resultado das humilhações sofridas pelo réu e de um forte sentimento de defesa da honra, atingida publicamente na comunidade. Os depoimentos dos presentes e do próprio réu no seu interrogatório confirmam que houve uma série de discussões e ofensas mútuas antecedentes ao crime. Além disso, há relatos de que a vítima tinha passado o dia consumindo bebida alcoólica, enquanto o acusado também alegou na Justiça haver bebido naquele dia, inclusive, encontrado com a vítima num bar da comunidade.

O fato é que as circunstâncias motivadoras do crime indicam que a defesa da honra atingida diante da comunidade contribuiu para o desenlace fatal. Tanto que no depoimento prestado na delegacia pela companheira da vítima, ela disse o seguinte:

\footnotetext{
"que em data não lembrada, a depoente afirma que passava por uma ponte que dar acesso a comunidade onde mora, encontrou o acusado (...), e indagou a ele o motivo que levou a cometer um desatino contra seu companheiro que estava entre a vida e a morte no leito do hospital, tendo o acusado lhe dito que no dia que ocorreu o fato, a vítima tinha lhe humilhado muito e aquilo subiu a sua cabeça e ele acusado resolveu se vingar, informando também a ela depoente que estava arrependido, pediulhes desculpas (...)."
} 


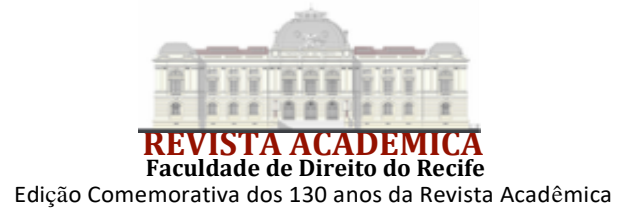

Nesse sentido, as situações motivadoras que envolvem os crimes de sangue, como também as situações de violência, especialmente aquelas vinculadas às comunidades populares, não podem ser analisadas apenas a partir dos pressupostos contidos no Direito posto. Há outros elementos, especialmente os socioculturais, que contribuem para desencadeamento dos conflitos e mortes violentas nas comunidades pobres. Isto não implica numa justificação para os crimes de modelo de silogismo lógico ou de argumentação dedutiva dos fenômenos sociais. As lutas e conflitos sociais fazem parte do cotidiano das pessoas, não apenas as ações consideradas "boas". De sorte que uma análise empírica dos fatos sociais pode contribuir para uma hermenêutica jurídica que se detenha nas motivações psicossociais, históricas e culturais, como essenciais na compreensão do comportamento humano.

Sabe-se que o desafio imposto ao homem pobre que tem a sua honra atingida, principalmente sua posição diante da comunidade, pode resultar numa reação violenta "legítima", inevitável e previsível de morte ao agressor. Diz Chalhoub que "o homem despossuído constrói sua identidade social a partir do que faz, e não, obviamente, a partir do que tem, pois, por definição, ele nada ou pouco tem." ( CHALHOUB, 2001) Nesse sentido, seria compreensível que a violência se institucionalizasse como decorrente de tensões e de conflitos inerentes a esses homens pobres, que apenas possuem, na vida miserável e indigna, a sua "honra", o seu "brio" para preservar.

Por sua vez, a justificação social, supostamente neutra da razão androcêntrica constituída socialmente pelas diferenças biológicas e pelos papeis sexuais entre homens e mulheres, no que diz respeito tanto ao plano físico quanto moral contribui para a formação do conceito de virilidade, relacionado ao aspecto ético como também a honra. A virilidade física do macho se faz representada pela força, bravura, garra, proeza, ousadia, masculinidade, potencia sexual etc. Nesse universo simbólico dominado pela masculinidade, a desonra, a perda do estatuto de homem frente aos desafios da vida diária, as contradições, disputas, agressões mútuas fazem reafirmar ou reacender a figura da virilidade do macho coerente com as práticas e hábitos regulares de uma sociedade pautada pela visão androcêntrica.

Além disso, a educação elementar inculca a separação de corpos de forma que a postura do macho se revela na maneira de andar, de erguer a cabeça ou os olhos, de olhar de frente, de forma a submeter na vida doméstica, no trabalho diário aqueles que estão sob seu domínio, no caso as mulheres, filhos, empregados.

A honra, considerada no sentido de um conjunto de aptidões (coragem física e moral, generosidade, magnanimidade etc.) seria para Bourdieu, o produto de um trabalho social de nominação e de inculcação, que se institui numa identidade social através da inscrição em uma natureza biológica que se torna hábitos ou uma lei social incorporada. Mas, o privilégio desfrutado na sociedade pelo macho também possui sua contrapartida - na tensão e na contenção permanente ao impor a todo o homem o dever contínuo de afirmar e de reafirmar diante de qualquer circunstância a virilidade, como resultado da sua submissão às exigências imanentes à ordem simbólica. Disso resulta que, a virilidade, entendida no espaço público e no espaço doméstico como capacidade reprodutiva, sexual e social também exige aptidão ao combate e ao exercício da violência (sobretudo a vingança), sendo acima de tudo uma carga. numa sociedade onde o conceito de dignidade da pessoa humana ainda não se tornou universal e generalizado para todas as classes sociais, a honra é uma espécie de estigma positivo que a família ou o indivíduo de família possui ou não possui. De forma que os atentados ou os crimes contra a honra é a morte social desses indivíduos. Talvez por isso, eles tenham que agir de maneira retributiva na reação àqueles que atentam contra ela. Os ofendidos e desonrados devem reparar o mal pelas próprias mãos e através de uma ação dotada de um mesmo teor destrutivo. É a lei de Talião. Não há a mediação legal do Estado na reparação do crime contra a honra ou a reputação desonrada por outros indivíduos.

\section{CONSIDERAÇÕES FINAIS}




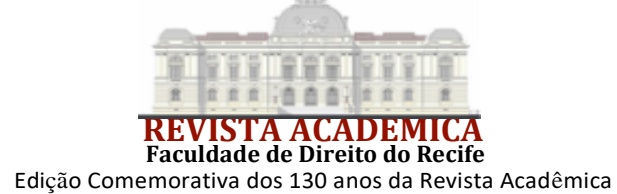

Penso que um dos grandes problemas enfrentados pelo Direito na atualidade estaria na busca de respostas "simples" para os complexos dilemas da vida em sociedade, a partir de um modelo argumentativo dedutivo. Para tanto, fazendo o uso de uma hermenêutica tradicional que apresente uma linguagem inteligível e que garanta a coesão entre as proposições fáticas e normativas. Hermenêutica essa de base tautológica, uma vez que a conclusão do silogismo lógico já está contida na premissa maior. Ora, a questão principal é provar a correção e a verdade da premissa menor. Tarefa que escapa a um mero raciocínio lógico-formal.

Sabe-se que os métodos característicos das ciências humanas se diferenciam dos métodos da matemática, em razão de seu caráter tautológico e generalizante. O ser humano é por natureza complexo. Isso implica na dificuldade de uma análise compreensiva das situações fáticas, a partir do método do silogismo lógico. Além disso, as mudanças e permanências ao longo da história, decorrentes das relações socioculturais repercutem na estrutura mental dos indivíduos, demandando uma hermenêutica que consiga dar conta do "mundo da vida", com seus conflitos e interfaces.

Nesse sentido, creio que a saída estaria numa justificação da decisão judicial que se pautasse em argumentos e decisões alcançadas de forma intersubjetiva, dialógica, já que a validade das pretensões (cognitiva, moral e estética do discurso) decorre de um processo argumentativo, obtido através do consenso racional entre interlocutores de boa fé. A linguagem seria o "médium" por excelência da interação segundo a teoria da ação comunicativa.

Por sua vez, os limites impostos pela linguagem implicam considerar também que ela não consegue dar conta da realidade. Porém, isto não significa desconsiderar os atos de fala por não conduzirem a consensos racionais, ou seja, aqueles que são estabelecidos visando um acordo entre os interlocutores sobre determinado assunto; já que se pressupõe o reconhecimento mútuo quanto à validade das pretensões, como sendo, verdadeira, sincera e justa, no que diz respeito à legitimidade da norma. Requer também considerar que os discursos visam à interação dos participantes que se comunicam livremente e em simetria.

Resta ainda, o reconhecimento dos limites inerentes aos métodos de interpretação das ciências humanas que podem contribuir para uma hermenêutica jurídica que enxergue a decisão judicial como sendo influenciadas pelas demais disciplinas que estudam o homem em sociedade, tais como a Sociologia, Antropologia, História etc.

Apostar numa outra hermenêutica - isto é, que se detenha nos conflitos a partir de outra perspectiva - traria à possibilidade de conduzir uma análise dos fatos numa direção reflexiva e complementar a direção dada pela norma, já que os acontecimentos do passado representam apenas versões, como observados pelos antropólogos, historiadores, sociólogos que se detêm no estudo de processos-crime de homicídios. Nisso, o conjunto probatório seria desencadeado num processo argumentativo que envolveria questões de interdisciplinaridade, indispensável na compreensão dos fenômenos sociais, contribuindo para uma decisão judicial mais próxima da verdade.

Seria possível obter uma justificação da decisão judicial que resultasse de acordos intersubjetivos e se construísse a partir de saberes interdisciplinares, no sentido de constituição de uma hermenêutica capaz de explicar as relações jurídicas da cotidianidade. Mas também colaborar na prescrição do comportamento no sentido formal do termo. Isto é, aproximar o Direito da realidade social, visando à melhoria da legislação vigente. Devido à impossibilidade da linguagem conseguir capturar a realidade, bem como em razão da própria dificuldade dos argumentos lógicos compreenderem o "mundo da vida", creio que a saída seja alargar o paradigma para um diálogo com as demais ciências sociais.

\section{REFERENCIAS}

A Dominação Masculina, 2a edição, RJ: Bertrand Brasil, 2002.

BOURDIEU, Pierre. O Poder Simbólico. Coleção Memória e Sociedade. Rio de Janeiro: Bertrand Brasil 


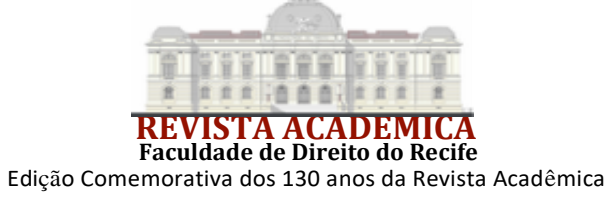

S/A, 1989.

BRASIL. Constituição (1988). Constituição da República Federativa do Brasil: promulgada em 05 de outubro de 1988. In: Presidência da República. Casa Civil. Subchefia para Assuntos Jurídicos. Brasília, 1988. Disponível em: 〈http://www.planalto.gov.br/ccivil_03/constituicao/constituicao.htm〉. Acesso em: 20 mai. 2020.

BRASIL. Decreto-Lei no 2.848, de 07 de dezembro de 1940. Código Penal. In: Presidência da República. Casa Civil. Subchefia para Assuntos Jurídicos. Rio de Janeiro, 1940. Disponível em: <http://www.planalto.gov.br/ccivil_03/decreto-lei/del2848compilado.htm>. Acesso em: 20 mai. 2020

BRASIL. Decreto-Lei no 3.689, de 03 de outubro de 1941. Código de Processo Penal. In: Presidência da República. Casa Civil. Subchefia para Assuntos Jurídicos. Rio de Janeiro, 1941. Disponível em: <http://www.planalto.gov.br/CCIVIL/Decreto-Lei?Del3689.htm>. Acesso em: 20 mai. 2020.

BRASIL. Lei n. 11.689/08, de 09 de junho de 2008. Altera dispositivos do Decreto-Lei $n^{\circ} 3.689$, de 3 de outubro de 1941 - Código de Processo Penal, relativos ao Tribunal do Júri, e dá outras providências. In: Presidência da República. Casa Civil. Subchefia para Assuntos Jurídicos. Brasília, 2003. Disponível em: <http://www.planalto.gov.br/ccivil_03/_Ato20072010/2008/Lei/111689.htm> Acesso em: 20 mai. 2020.

CHALHOUB, Sidney. Trabalho, Lar e Botequim. O cotidiano dos trabalhadores no Rio de Janeiro da belle époque. 2. ed. São Paulo: Unicamp, 2001.

COLARES, Virgínia. (RE) PENSANDO A RELAÇÃO LINGUAGEM E DIREITO. Disponível em: <http://www.publicadireito.com.br/artigos/?cod=27253445de7e4ce1 $>$.

CORRÊA. Mariza. Morte em Família: representações jurídicas de papéis sexuais. Rio de Janeiro: Graal, 1983.

EIRÓ GUNDIM, Wagner. Hidras e Hércules - A relação circular entre princípios e regras. Revista Da Faculdade De Direito De São Bernardo Do Campo, 21(2). Recuperado de <https://revistas.direitosbc.br/index.php/fdsbc/article/view/793>. Acesso: 15 mai. 2020.

FAUSTO, Boris. Crime e cotidiano. A criminalidade em São Paulo (1890-1920). São Paulo: USP. 2. ed. 2001.

FERNANDES, Ricardo Vieira de Carvalho. BICALHO, Guilherme Pereira Dolabella. Do positivismo ao pós-positivismo jurídico - $\mathrm{O}$ atual paradigma jusfilosófico constitucional. Revista de informação legislativa, v. $48, \quad$ n. 189 , p. 105-131, jan./mar. 2011. Disponível em: <https://www2.senado.leg.br/bdsf/item/id/242864>. Acesso em: 18 mai. 2020.

FOUCAULT, Michel. A verdade e as formas jurídicas. Rio de Janeiro: NAU, 1973.

FOUCAULT. Michel. A Microfísica do Poder. Rio, Forense, 1976

FRANCO, Maria Sylvia de Carvalho. Homens livres na ordem escravocrata. 4. ed. São Paulo: UNESP, 1997.

GOMES. Luiz Flávio GOMES (Org). Código Penal, Código de Processo Penal, Constituição Federal. 6. Ed. São Paulo: editora Revista dos Tribunais, 2004.

HABERMAS, Junger. La teoria de la accion comunicativa. Buenos Aires: Taurus, 1987. 
HABERMAS, Jürgen. Teoria da la Acción Comunicativa. Trad. Manuel Jiménez Redondo. Madrid: Taurus, 1987. v. I.

KANT, Immanuel. Os Pensadores. São Paulo: Abril Cultural, 1980.

MARCONDES, Danilo. Desfazendo mitos sobre a pragmática. Disponível em: <http://revistaalceuacervo.com.puc-rio.br/media/alceu_n1_Danilo.pdf $>$. Acesso em: 12 abr. 2018.

NERI, Edlene Maria. Ensaios Teóricos. Filosofia, Política e Direito. Curitiba: Brazian Publish, 2021.

NIETZSCHE, Frederico. A vontade de Poder. Globo, 1970.

NIETZSCHE. Frederico. Assim falou Zaratrusta. São Paulo: Hemus, 1977.

PARINI, Pedro. O raciocínio dedutivo como possível estrutura lógica da argumentação judicial: silogismo versus entimema a partir da contraposição entre as teorias de Neil MacCormick e Katharina Sabota. Disponível em: <http://www.publicadireito.com.br/conpedi/manaus/arquivos/anais/XIVCongresso/178.pdf.> Acessado em 16 mai. 2020.

ROSAS, Alexandre Morais da. Variáveis ocultas e efeito borboleta na decisão penal. Revista Consultor Jurídico. Disponível em: <https://www.conjur.com.br/2014-mar-22/diarioclasse-variaveis-ocultas-efeito-borboleta-decisao-penal>. Acesso em: 15 mar. 2020.

SANTOS, Boaventura de Souza. A Gramática do Tempo. São Paulo: Cortez, 2006.

SPAREMBERGER, Raquel. A natureza da Ciência Jurídica: a polêmica entre o normativismo de Hans Kelsen e o sociologismo (hermenêutica do Direito vivo) de Eugen Ehrlich. In: Revista Direito em debate. Ano XI, nº 20, jul./dez.2003.

STRECK, Lenio Luiz. Jurisdição e ausência de uma teoria da decisão. Revista de Derecho de la Pontifícia Universidad Católica de Valparaíso XLI (Valparaíso, Chile, 2013, $2^{\circ}$ Semestre). Universidade do Vale do Rio dos Sinos (Unisinos), São Leopoldo - RS.

WITTGESTEIN, Ludwig. Os Pensadores. São Paulo: Abril Cultural, 1991. 